\title{
Inventory-Based Analysis of Greenhouse Gas Emission from the Cement Sector in Thailand
}

\author{
Chittin Tangthieng \\ Department of Mechanical Engineering, Faculty of Engineering, Chulalongkorn Universiry, Phayathai Road, \\ Patumwan, Bangkok 10330, Thailand \\ E-mail: qed690@yahoo.com
}

\begin{abstract}
The GHG inventory from the cement sector in Thailand is analyzed by using the CSI protocol. The data are provided by five participated cement industries in the country starting from the year 2001 to 2014. The key performance indices corresponding to the GHG reduction technologies are calculated and presented. The results indicate that the annual average of the direct $\mathrm{CO}_{2}$ emission from the cement sector is 33.1 million tonnes of $\mathrm{CO}_{2}$, which contributes nearly $15 \%$ of the total national GHG emission. This amount of $\mathrm{CO}_{2}$ emission originates from the calcination and the fuel combustion parts by 21.3 and 11.8 million tonnes of $\mathrm{CO}_{2}$, respectively. The average specific net and gross $\mathrm{CO}_{2}$ emissions are 727 and $733 \mathrm{~kg}$ of $\mathrm{CO}_{2}$ per tonne cementitious, respectively. The average specific indirect $\mathrm{CO}_{2}$ emission from external electricity production is $60.5 \mathrm{~kg}$ of $\mathrm{CO}_{2}$ per tonne cement. The average specific thermal and electrical consumption is $3.32 \mathrm{GJ}$ per tonne clinker and $117 \mathrm{kWh}$ per tonne cement, respectively. The average alternative and bio fuel thermal ratios are 2.51 and $5.24 \%$, respectively. The average clinker-to-cement ratio is $82.4 \%$. From the analysis, it is indicated that the use of the bio fuels have been an effective mitigation action in the past decade, and the use of the alternative fuels have been employed in the last few years. The implementation of the electrical energy efficiency and the WHR unit causes the specific indirect $\mathrm{CO}_{2}$ emission from external electricity generation decreasing steadily over the past decade. On the other hand, the key technology for the direct $\mathrm{CO}_{2}$ reduction potential is the clinker substitution. The availability of the clinker substitutes in the country is very limited, but opportunity of using these substitutes should be increased in the future.
\end{abstract}

Keywords: GHG emission, GHG inventory, cement sector.

ENGINEERING JOURNAL Volume 21 Issue 5

Received 23 February 2017

Accepted 24 April 2017

Published 29 September 2017

Online at http://www.engj.org/

DOI:10.4186/ej.2017.21.5.125 


\section{Introduction}

Since the past few decades, the GHG emission has been extensively calculated and studied due to the awareness of the global warming effects. The purposes for the study are to establish a baseline case for references, to track the GHG emission, to promote sustainable development, and to facilitate the mitigation planning. The GHG inventory can be roughly distinguished into different levels: national, sectoral, and corporate ones. The national GHG inventory is necessary for the international climatechange arrangement of the participating countries to keep tracking the GHG emissions, to develop appropriate national policies, and to project future emissions. The sectoral GHG inventory is beneficial for developing the appropriate mitigation plans, which could be different in each sector. On the other hand, the corporate GHG inventory is used as a criterion for the worldwide acceptance between organizations.

In Thailand, the GHG inventory and mitigation options have been calculated and reported by many researchers. The potential of GHG mitigations in different scenarios including the effect of fuel choices on the GHG-related power generation sector were evaluated [1,2]. The input-output analysis of the GHG emission was performed based on the IPCC guideline for different industrial sectors. The result indicated that the cement industry has the highest GHG emission among the industrial ones [3]. The GHG inventory of the transport sector in Thailand was presented for the GHG emission reduction potentials, together with several mitigation options such as fuel switching and use of high performance vehicles $[4,5]$. The GHG reduction potential of the transport sector in Thailand by using ethanol as an alternative fuel is analyzed by developing the energy demand modeling [6]. For the power sector in Thailand, comparison between different scenarios was made to present GHG-reduction opportunities and constraints in both technical and policy aspects [7]. Investigation and analysis of the life-cycle GHG emission from several bio fuels for the power generation is performed. The contribution to the GHG savings is approximately 0.5 million tonnes of $\mathrm{CO}_{2}$ per year [8]. The methane emission from solid waste disposal sites in Thailand is estimated using three different approaches with the feasible reduction potential of the landfill gas utilization [9]. The benefit-cost analysis of different options is used to study the GHG emissions of the forestry sector in Thailand [10]. Several mitigation measures for the $\mathrm{CO}_{2}$ reduction potentials are proposed in Thai residential and building sectors. It is estimated that $35 \%$ of the $\mathrm{CO}_{2}$ emission is reduced by the year 2050 [11]. In overall, based on Thailand GHG report in 2011, the total emission is 234 million tonnes of $\mathrm{CO}_{2}$, which is categorized into energy, industrial processes, agriculture, LULUCF, and waste of 223, 18, 53, -71, and 11 million tonnes of $\mathrm{CO}_{2}$. The cement sector contributes approximately 36 million tonnes of $\mathrm{CO}_{2}$ or $15 \%$ of the net national GHG emission. As a result, the GHG emission reduction in the cement sector would be a major contribution for the national one.

In case of the Thai cement sector, the studies related to the GHG emissions and reduction potentials have been performed. The $\mathrm{CO}_{2}$ abatement cost curves of different technologies were developed and discussed in 2005. It is estimated that the total $\mathrm{CO}_{2}$ abatement potential is 3.1 million tonnes of $\mathrm{CO}_{2}$ per year [12]. The assessment of the effective $\mathrm{CO}_{2}$-reduction potentials in both technical and economic aspects of Thai cement industry is performed. The results indicates that the cost-effective potentials for electrical and fuel saving in 2005 are 8 and 16 percent, respectively $[13,14]$. To identify the opportunities for nationally appropriate mitigation actions for Thai cement sector, this present study focuses on the inventory-based analysis of the GHG emission starting from 2001 to 2014. By acquiring the data from five Thai cement companies, the GHG inventory is compiled. The results are presented on the basis of several key performance indices used to indicate the $\mathrm{CO}_{2}$ reduction potentials for the key technologies.

\section{Methodology}

\subsection{Scope of Study and Data Sources}

The first step to develop the GHG inventory is to define the boundary of the inventory, which includes raw material quarry, raw material preparation, clinker making process at the kiln, and cement making process as shown in Fig. 1. The protocol developed by the Cement Sustainability Initiative (CSI) will be employed to calculate the GHG emission [15]. It should be noted that the CSI protocol has been widely implemented by Thai cement industries to report the GHG emission. Thus, using the CSI protocol will prevent duplication of work. The data are provided by five participated cement companies in Thailand starting from the year 2001 to 2014. 


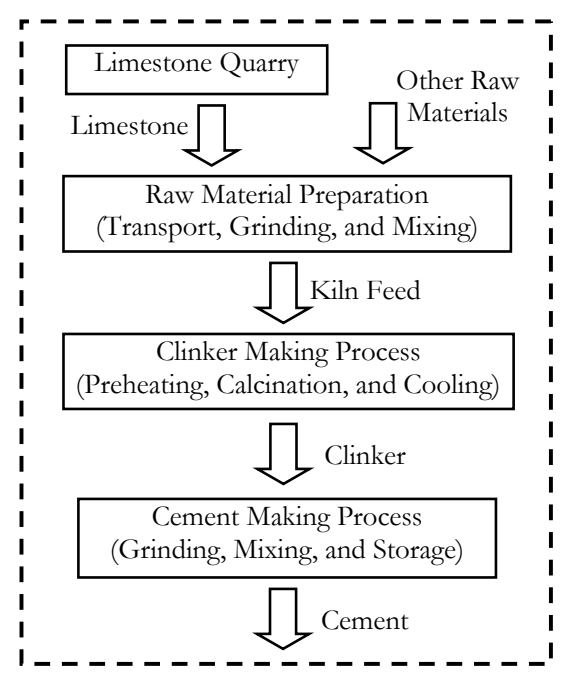

Fig. 1. The boundary under consideration.

\subsection{GHG Emission Calculation}

In the CSI protocol, the GHG emission is calculated from three parts including the direct emission from the calcination, the direct emission from the fuel combustion, and the indirect emission from external electricity production. The first two parts are equivalent to the energy sector and the IPPU (industrial processes and product use) sector in the 2006 IPCC guidelines [16]. Based on the CSI protocol related to the non- $\mathrm{CO}_{2}$ GHG emission, it should be noted that methane are typically small due to the high temperature combustion in a kiln whereas other non- $\mathrm{CO}_{2} \mathrm{GHG}$ are irrelevant in the kiln system. As a result, only the $\mathrm{CO}_{2}$ emission will be considered in this present study. The detailed calculations are as follows

\section{1) Direct Emission from Calcination}

The $\mathrm{CO}_{2}$ emission from calcination originates from the decomposition of $\mathrm{CaCO}_{3}$ and $\mathrm{MgCO}_{3}$ in raw materials into $\mathrm{CaO}$ and $\mathrm{MgO}$, respectively, and $\mathrm{CO}_{2}$ as a by-product. Based on the CSI protocol, the $\mathrm{CO}_{2}$ emission from calcination is composed of four parts: 1) the emission from produced clinker, 2) the emission from bypass dust, 3) the emission from cement kiln dust, and 4) the emission from organic carbon in raw materials. The first part is the majority one that emits most $\mathrm{CO}_{2}$ from calcination. For the second part, because the amount of bypass dust, defined as fully-calcined dust discarded from the kiln system, is relatively small compared to the produced clinker, the emission from the bypass dust is neglected. On the opposite site to the bypass dust, cement kiln dust is defined as partially-calcined dust discarded from the kiln system. Since a dry-kiln process, mostly implemented in Thai cement industries, has a very high degree of calcination conversion, the emission from cement kiln dust is omitted. Lastly, the fourth part represents the conversion of organic carbon in raw materials into $\mathrm{CO}_{2}$ during the calcination process.

From the above assumptions, the equation of the direct emission of $\mathrm{CO}_{2}$ from calcination can be written as

$$
G H G_{\text {Calc }}=m_{C l i} E F_{C l i}+3.664 m_{C l i} R C f_{T O C}
$$

For CSI protocol, the default value of $\mathrm{EF}_{\mathrm{Cli}}$ is $525 \mathrm{~kg} \mathrm{CO}_{2}$ per tonne of clinker. However, to obtain more accurate results, it is recommended to determine the value of $\mathrm{EF}_{\mathrm{Cli}}$ from the measured $\mathrm{CaO}$ and $\mathrm{MgO}$ contents of the clinker. Thus, by averaging the $\mathrm{CaO}$ and $\mathrm{MgO}$ contents with the amount of produced clinker from five Thai cement industries, the value of $\mathrm{EF}_{\mathrm{Cli}}$ of $540.6 \mathrm{~kg} \mathrm{CO}_{2}$ per tonne of clinker will be used in this present study. The default values of $\mathrm{RC}$ and $\mathrm{f}_{\mathrm{TOC}}$ are 1.55 and $0.2 \%$, respectively, based on the CSI protocol recommendation. 


\section{2) Direct Emission from Fuel Combustion}

The $\mathrm{CO}_{2}$ emission from fuel combustion includes the emission from conventional fossil fuels and alternative fuels such as used oil, solvents, plastics, tires, any other waste etc. On the other hand, bio fuels such as biomass, bagasse, rice husk, wood chips, saw dust, etc is considered as climate neutral sources. Thus, the $\mathrm{CO}_{2}$ emission from bio fuels will be reported as a memorandum item. Based on the defined boundary of the inventory, the fuel combustion from both kiln and non-kiln process is taken into account.

The direct emission of $\mathrm{CO}_{2}$ from fuel combustion can be determined from

$$
G H G_{\text {Comb }}=\sum_{\text {All Fuels }} m_{\text {Fuel }} L H V_{\text {Fuel }} E F_{\text {Fuel }}
$$

The values of LHV of fuels are obtained from the individual company as the first priority. In case of the absence of those values, the default values proposed by the department of alternative energy development and efficiency (DEDE) will be used [17]. The emission factors of the fuel are obtained by the default values from the IPCC and CSI databases $[15,16]$.

\section{3) Indirect Emission from External Electricity Production}

This indirect emission originates from the electric energy consumption of grid electricity, which emits $\mathrm{CO}_{2}$ from the power plant outside the system boundary. The indirect emission can be determined from

$$
G H G_{\text {Elec }}=P_{\text {Elec }} E F_{\text {Elec }}
$$

The emission factor of grid electricity in Thailand, obtained from Thailand Greenhouse Gas Management Organization the, is 0.5813 tonne of $\mathrm{CO}_{2}$ per $\mathrm{kWh}$ [18]. It should be noted that most cement industries have already installed the waste heat recovery unit from the kiln system to generate electricity. This unit will be considered as the same entity as the cement plant. Therefore, the net electric energy consumption from the plant will take the effect of the electric energy reduction from this waste heat recovery unit into account.

\subsection{Performance Indices}

In order to provide sufficient information for monitoring and reporting, the performance indices for the GHG emission are given. Each index will reflect the emission activity in different perspectives. These performance indices include 1) the absolute direct and indirect emissions, 2) the specific direct and indirect emissions, 3) the specific thermal consumption at the kiln, 4) the alternative and bio fuel thermal ratios, 5) the specific electrical consumption, and 6) the clinker-to-cement ratio. The results of some performance indices will be compared with the global cement database obtained from the GNR website [19].

The described performance indices will reflect the $\mathrm{CO}_{2}$ reduction potential based on the technology roadmap proposed by the international energy agency [20]. The key technologies for $\mathrm{CO}_{2}$ reduction in the cement industry are categorized into four groups: the energy efficiency, the fuel switching, the clinker substitution, and the carbon capture and storage (CCS). The energy efficiency includes both thermal energy efficiency for the kiln system and electrical energy efficiency for the overall cement production process. The fuel switching represent the use of lower carbon-intensive fuels or carbon-free fuels compared to the conventional fossil fuels such as the alterative or bio fuels. The clinker substitution is to replace the portion of clinker in the cement mix with other lower carbon-intensive materials. The CCS is the carbon-capturing process before releasing to the atmosphere. In this present study, only the first three technologies will be considered due to the limitation of the implementation of the CCS in the country.

\section{Results and Discussion}

To ensure that the acquired data are enough to represent the majority of the cement groups, the clinker, cementitious, and cement productions from this present study are depicted in Fig. 2. The clinker production is the produced clinker from the kiln system including sold clinker and producing-cement clinker. On the other hand, the cement production is the combination of producing-cement clinker, 
bought clinker, and other binding materials. The cementitious product is all produced clinker from the kiln system excluding bought clinker, plus other binding materials. The clinker production in this study contributes nearly $100 \%$ of the national cement production obtained by the office of industrial economics [21]. According to Fig. 2, the amount of the clinker, cementitious, and cement productions gradually increases from 2001 to 2014 with the annual average values of 38.6, 45.2, and 37.4 million tonnes, respectively.

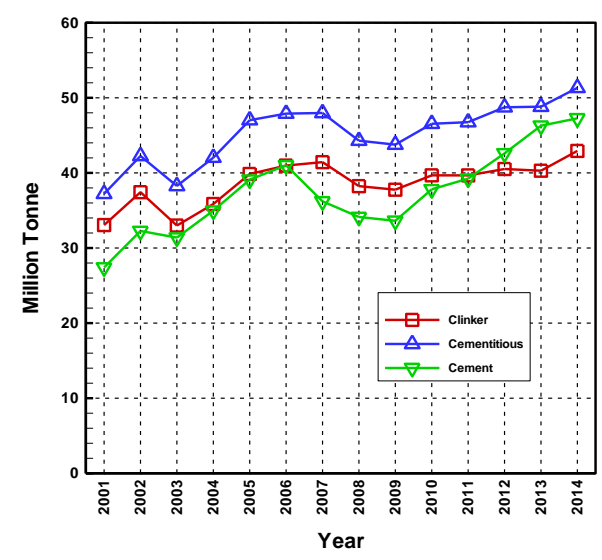

Fig. 2. The clinker, cementitious and cement productions.

Figure 3 depicts the absolute direct emissions from calcination and fuel combustion. It can be seen that the direct emissions from calcination will follow the similar trend to the clinker production. With the combination of these two parts, the total absolute direct emission from the cement industry varies from 28.4 to 36.9 million tonnes of $\mathrm{CO}_{2}$ from 2001 to 2014 with the annual average value of 33.1 million tonnes of $\mathrm{CO}_{2}$. This amount is approximately $15 \%$ of the total national $\mathrm{CO}_{2}$ emission. In average, the contribution of the calcination part is approximately $64.4 \%$ whereas that of the fuel combustion part is $35.6 \%$, corresponding to the annual average values of 21.3 and 11.8 million tonnes, respectively.

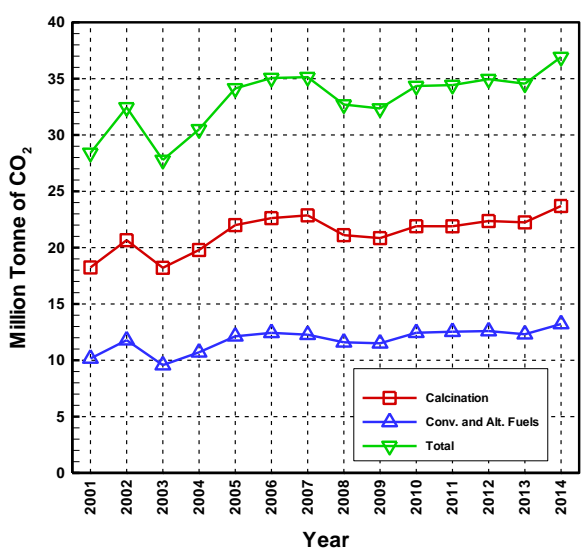

Fig. 3. The absolute direct emissions from calcination and fuel combustion.

The absolute direct emission from fuel combustion of various fuel types is depicted in Fig. 4. Based on the total amount of 11.8 million tonnes of $\mathrm{CO}_{2}$ emission per year released from the fuel combustion, the conventional fuel and alternative fuel contribute the $\mathrm{CO}_{2}$ emission by 11.5 and 0.3 million tonnes of $\mathrm{CO}_{2}$ per year in average. This indicates that the majority of the $\mathrm{CO}_{2}$ emission source in the fuel combustion part is still the conventional fossil fuel approximately by $97.8 \%$. On the other hand, the $\mathrm{CO}_{2}$ emission saved by the use of the bio fuel is approximately 0.7 million tonnes of $\mathrm{CO}_{2}$ per year in average. 


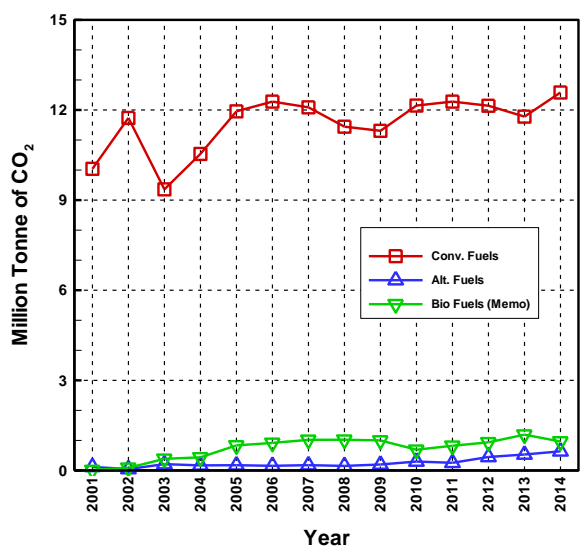

Fig. 4. The absolute direct emissions from fuel combustion of various fuel types.

Figure 5 illustrates the variation of the absolute indirect $\mathrm{CO}_{2}$ emission from external electricity production. The amount of the indirect $\mathrm{CO}_{2}$ emission is roughly the same throughout the period under consideration, which is approximately 2.3 million tonnes of $\mathrm{CO}_{2}$ per year in average.

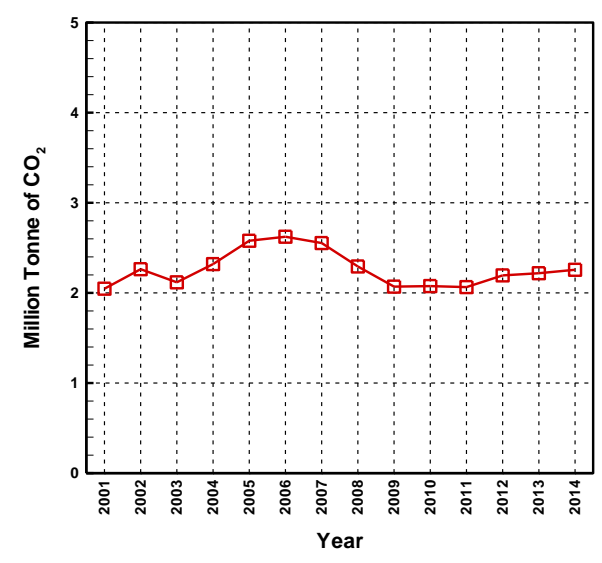

Fig. 5. The absolute indirect emission from external electricity production.

Figure 6 depicts the comparison between the specific direct net and gross $\mathrm{CO}_{2}$ emissions from this present study and the GNR world database. According to the definition from the CSI protocol, the net $\mathrm{CO}_{2}$ emission includes all direct emission sources except for the alternative fuel whereas the gross one takes that alternative fuel into account. Quantitatively, the average specific net and gross $\mathrm{CO}_{2}$ emissions from this study are 727 and $733 \mathrm{~kg}$ of $\mathrm{CO}_{2}$ per tonne cementitious, respectively. Those two values from the GNR world database are 639 and $659 \mathrm{~kg}$ of $\mathrm{CO}_{2}$ per tonne cementitious, respectively. The difference between those two data sources is approximately $80 \mathrm{~kg}$ of $\mathrm{CO}_{2}$ per tonne cementitious or $11 \%$ reduction of the direct $\mathrm{CO}_{2}$ emission. This $\mathrm{CO}_{2}$ reduction can be achieved by utilizing the energy efficiency technologies, the alternative or bio fuels, and the clinker substitution. 


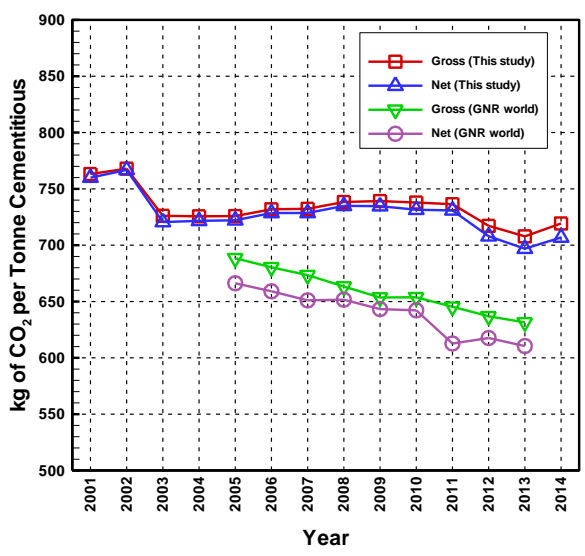

Fig. 6. Comparison between the specific direct net and gross emissions from this present study and the GNR world database.

Figure 7 illustrates the specific indirect emission from external electricity production. The average value of this is $60.5 \mathrm{~kg}$ of $\mathrm{CO}_{2}$ per tonne cement. It is noticed that the trend of this value continuously drops after 2008. By considering Figs. 2 and 5, it can be seen that after 2008 the absolute indirect emission remains the same whereas the cement production keep increasing. This is due to the implementation of the waste heat recovery (WHR) unit to the kiln system. This WHR unit utilizes the waste heat from the stack exhaust gas to produce electricity via the steam power generation system. Based on the cement manufacturer, in practice the WHR unit can save approximately one third of the electrical power consumption from the entire facility.

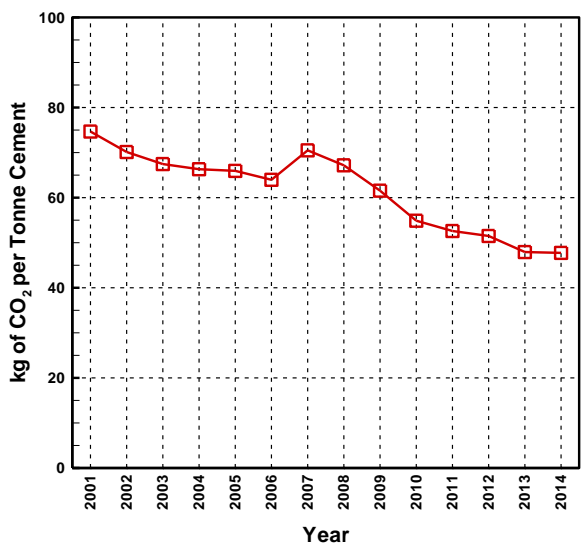

Fig. 7. The specific indirect emission from external electricity production.

Figure 8 depicts the comparison between the specific thermal consumptions from this study and the GNR world database. The average specific thermal consumption from this study at the kiln is 3.32 GJ per tonne clinker whereas that value from the GNR world database is $3.61 \mathrm{GJ}$ per tonne clinker. The trend of the specific thermal consumption from this study gradually increases starting from 2003 and reaches the maximum about 3.45 GJ per tonne clinker from 2011 to 2013 . This is mainly due to the effect of the implementation of the bio fuel shown in Figs. 4 and 9. The fluctuation of the heating value of the bio fuel from its moisture content and its component can cause the significant increase of the specific thermal consumption of the kiln. In case of the increase of the bio thermal ratio from 0.43 to $6.33 \%$, the specific thermal consumption increases from 3.22 to 3.45 GJ per tonne clinker. On the contrary, the specific thermal consumption from the GNR world database gradually decreases from 3.69 to 3.50 GJ per tonne clinker. In general, the specific thermal consumption will decrease due to the implementation of the 
thermal energy efficiency program such as reduction of heat loss, installation of load preheater, and phasing out an obsolete technology for the kiln.

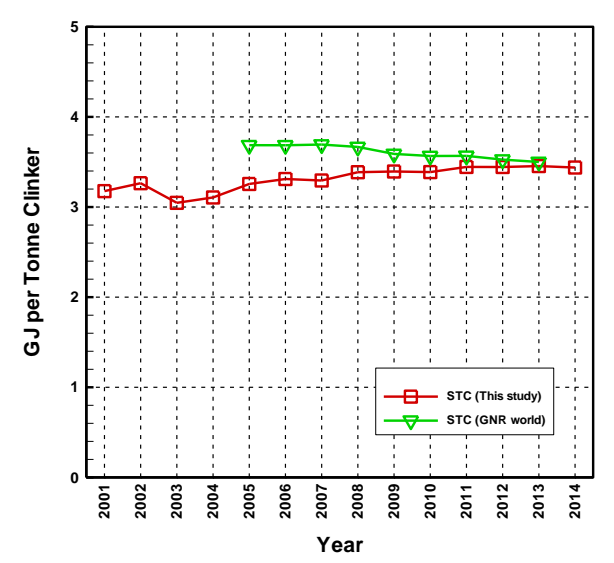

Fig. 8. Comparison between the specific thermal consumptions from this present study and the GNR world database.

Figure 9 illustrates comparison between the alternative and bio fuel thermal ratios from this present study and the GNR world database. The average values of the alternative and bio fuel thermal ratios are 2.51 and $5.24 \%$, respectively. The trend of the alternative fuel thermal ratio remains the same from 2001 to 2009 whereas the upward trend is noticeable after 2009. On the other hand, the trend of the bio fuel thermal ratio is increasing from 2001, but it reaches the limit at around 2006. This may be because of the limited amount of the bio fuels available to the cement industries, leading to the exploitation of the alternative fuels beyond 2006. The average values of the alternative and bio thermal ratios from the GNR world database are approximately 8.12 and $3.57 \%$, respectively. The trend of both thermal ratios is increasing. From this global trend, the alternative fuel seems to be the first choice for fuel switching from the conventional fossil fuel, rather than the bio fuel. To do so, the waste management, especially the waste separation, is the key factor to implement the alternative fuel efficiently.

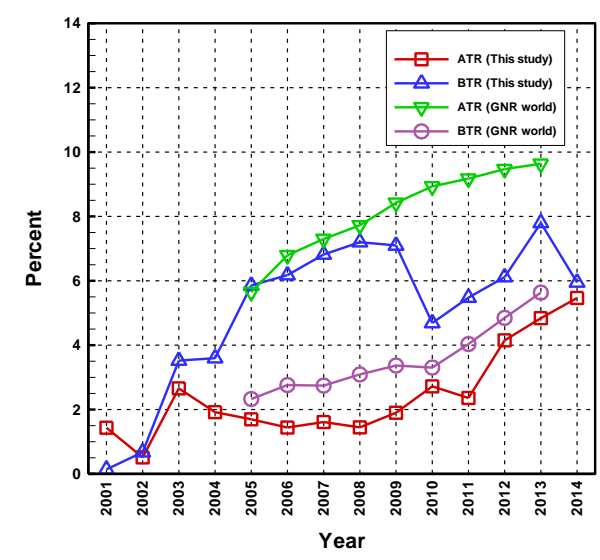

Fig. 9. Comparison between the alternative and bio fuel thermal ratios from this present study and the GNR world database.

Figure 10 depicts the comparison between the specific electrical consumptions from this present study and the GNR world database. Note that the specific electrical consumption will indicate how efficient the electrical energy is used in the cement production process. Therefore, the implementation of the WHR unit will not affect the value of the specific electrical consumption. The results show that the average specific electrical consumption from this study is $117 \mathrm{kWh}$ per tonne cement whereas that value from the GNR 
world database is $108 \mathrm{kWh}$ per tonne cement. The specific electrical consumption from this study gradually decreases starting from 2001 to 2006, rebounds back in 2007, and starts decreasing again from 2008 to 2014. This behavior is due to the effect of the cement production shown in Fig. 2. However, some of the electrical energy efficiency programs have been adopted such as the high-efficiency grinding technology, the high-efficiency classifiers, and the variable-speed-drive motor, leading to the reduction of the specific energy consumption during the last few years. The same effect of the electrical energy efficiency program is observed to the global trend.

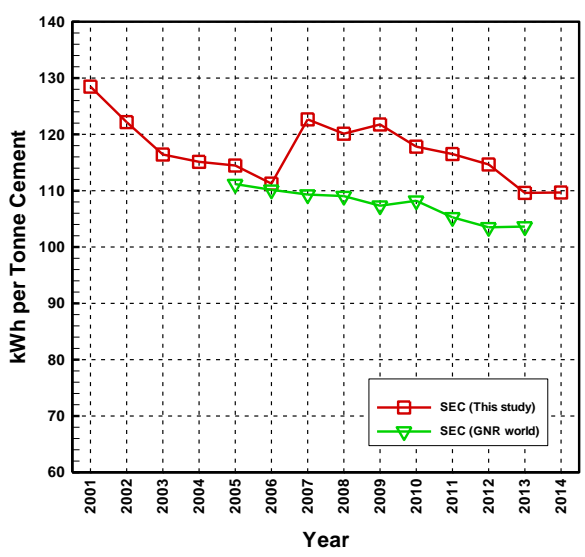

Fig. 10. Comparison between the specific electrical consumptions from this present study and the GNR world database.

Figure 11 illustrates comparison between the clinker-to-cement ratio from this present study and the GNR world database. The average clinker-to-cement ratios from this present study and the GNR world database are 82.4 and $76.3 \%$, respectively. The discrepancy between these two values comes from the implementation of the clinker substitution by replacing the portion of clinker in the cement mix with other lower carbon-intensive materials such as fly ash from a coal-fired power plant, ground blast-furnace slag, and natural or artificial pozzolanic materials. Unlike the energy efficiency or the fuel switching technologies which affects the $\mathrm{CO}_{2}$ emission on the fuel-consumption part, the clinker substitution will reduce the $\mathrm{CO}_{2}$ emission in both calcination and fuel-consumption ones, leading to a major impact on the $\mathrm{CO}_{2}$ emission reduction. It is estimated that if the average clinker-to-cement ratio of the Thai cement industries decreases from $82.4 \%$ to the average global value of $76.3 \%$, the specific direct gross emissions will decrease from 733 to $678 \mathrm{~kg}$ of $\mathrm{CO}_{2}$ per tonne cementitious. As a result, the specific direct gross emission would have been reduced to the same level as the global value as shown in Fig. 6. However, because of a few numbers of the existing coal-fired power plants and the absence of the blast furnace, and the active volcanic region, the availability of these clinker substitutes in Thailand is very limited. Since the project of utilizing coal-fired power plants has been included in the power development plan (PDP2015), the opportunity of using fly ash as a clinker substitute should be increased in the future. It should be noted that the effect of the clinker substitutes on the cement characteristics is also one of the major drawbacks of the implementation of this clinker substitution program. 


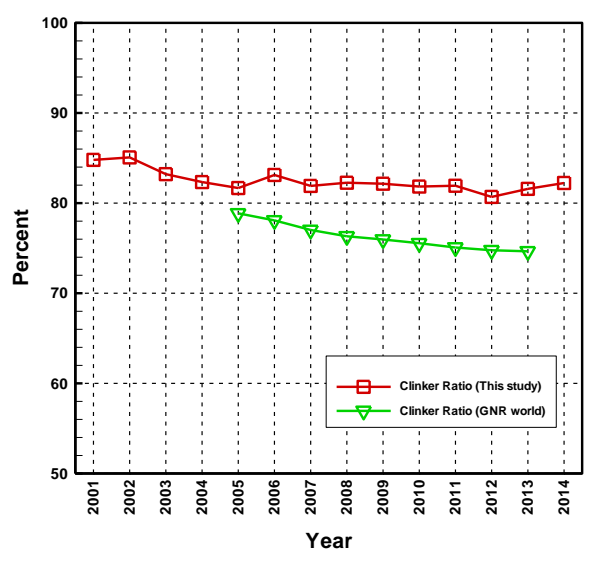

Fig. 11. Comparison between the clinker-to-cement ratio from this present study and the GNR world database.

\section{Conclusions}

The inventory-based analysis of the GHG emission from the Thai cement sector is performed in this study. By using the CSI protocol, the GHG inventory is calculated and presented in terms of the key performance indices, related to the corresponding GHG reduction technologies. The results show that the annual average of the direct $\mathrm{CO}_{2}$ emission from the cement sector is 33.1 million tonnes of $\mathrm{CO}_{2}$. This amount is composed of 21.3 and 11.8 million tonnes of $\mathrm{CO}_{2}$ from the calcination and fuel consumption parts, respectively. The majority of the $\mathrm{CO}_{2}$ emission from the fuel combustion originates from the conventional fossil fuels by approximately $98 \%$. The average specific net and gross $\mathrm{CO}_{2}$ emissions are 727 and $733 \mathrm{~kg}$ of $\mathrm{CO}_{2}$ per tonne cementitious, respectively. On the other hand, the average specific indirect $\mathrm{CO}_{2}$ emission from external electricity production is $60.5 \mathrm{~kg}$ of $\mathrm{CO}_{2}$ per tonne cement. The average specific thermal and electrical consumption is $3.32 \mathrm{GJ}$ per tonne clinker and $117 \mathrm{kWh}$ per tonne cement, respectively. The average alternative and bio fuel thermal ratios are 2.51 and $5.24 \%$, respectively. The average clinker-tocement ratio is $82.4 \%$.

Based on these results and the comparison with the GNR world database, it is indicated that the use of the bio fuels have been an effective mitigation action to reduce the direct $\mathrm{CO}_{2}$ emission in Thailand for the past decade until the amount of the bio fuels reaches its limit. However, this action can cause a negative effect to the thermal energy efficiency at the kiln. As a result, during the past few years the mitigation action turns the attention to the use of the alternative fuels. This national trend of implementing the alternative and bio fuels is opposed to the global trend where the alternative fuel is preferable than the bio one. On the other hand, the electrical energy efficiency and the WHR unit results in the steady reduction of the specific indirect $\mathrm{CO}_{2}$ emission from external electricity generation. Because the availability of the clinker substitutes in the country is quite limited, the value of the average clinker-to-cement ratio is still higher than the global one. It is estimated that the specific direct gross emission will decrease from 733 to $678 \mathrm{~kg}$ of $\mathrm{CO}_{2}$ per tonne cementitious if the average clinker-to-cement ratio decreases from the current average value of $82.4 \%$ to the global average one of $76.3 \%$. Thus, the clinker substitution is one of the key potential technologies to decrease the direct $\mathrm{CO}_{2}$ emission in the future.

\section{Acknowledgements}

The author is grateful for the financial support of this research project from Thailand Greenhouse Gas Organization (TGO). The author is also grateful for the information support provided by the participated cement companies. 


\section{Nomenclature}

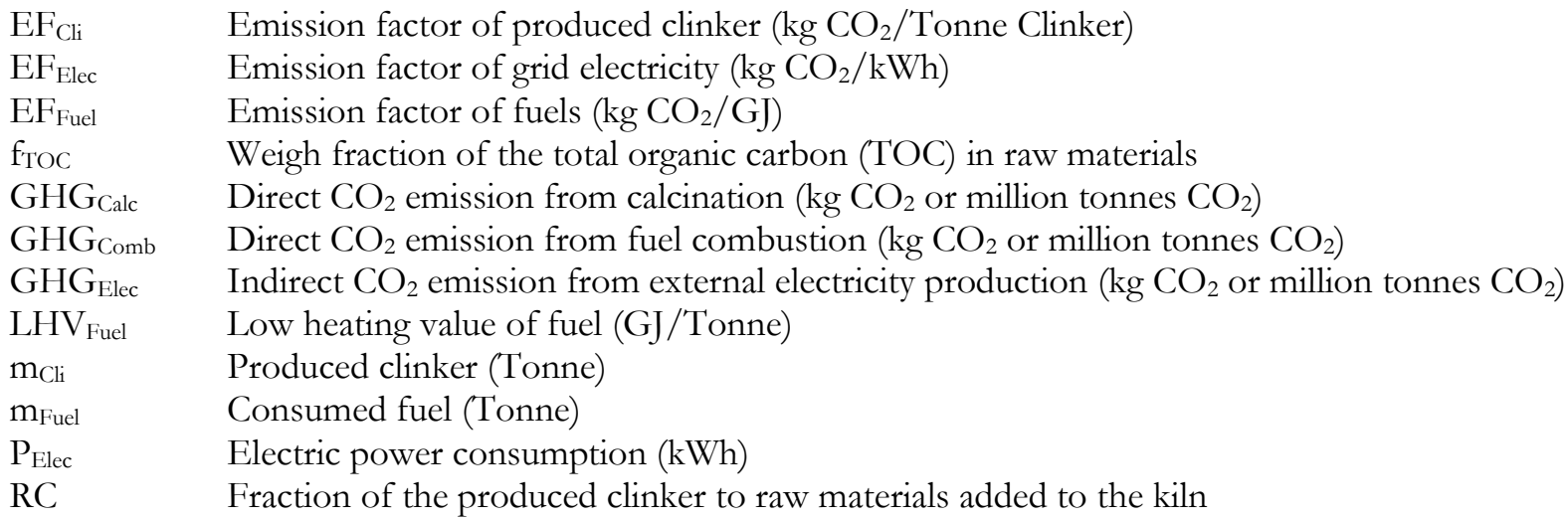

\section{References}

[1] W. Wangjiraniran and B. Eua-arporn, "A study of fuel options for power generation in Thailand," Engineering Journal, vol. 14, no. 3, pp. 35-44, 2010.

[2] W. Wangjiraniran and B. Eua-arporn, "A study on energy-related GHG mitigation scenario in Thailand," Engineering Journal, vol. 16, no. 2, pp. 19-29, 2012.

[3] B. Limmeechokchaia and P. Suksuntornsiri, "Embedded energy and total greenhouse gas emissions in final consumptions within Thailand,” Renewable and Sustainable Energy Reviews, vol. 11, no. 2, pp. 259281, 2007.

[4] J. Pongthanaisawan and C. Sorapipatana, "Greenhouse gas emissions from Thailand's transport sector: Trends and mitigation options," Applied Energy, vol. 101, pp. 288-298, 2013.

[5] S. Phoualavanh and B. Limmeechokchai, "Scenario-based analysis of $\mathrm{CO}_{2}$ mitigation potential in the transport sector: comparison between Lao PDR and Thailand," Engineering Journal, vol. 20, no. 4, pp. 111-119, 2016.

[6] N. Chollacoopa, P. Saisirirata, S. Sukkasia, M. Tongroona, T. Fukudab, A. Fukudac, and S. Nivitchanyong, "Potential of greenhouse gas emission reduction in Thai road transport by ethanol bus technology," Applied Energy, vol. 102, pp. 112-123, 2013.

[7] Y. Mulugettaa, N. Mantajitb, and T. Jacksona, "Power sector scenarios for Thailand: an exploratory analysis 2002-2022,” Energy Policy, vol. 35, no. 6, pp. 3256-3269, 2007.

[8] W. Siemers, "Greenhouse gas balance for electricity production from biomass resources in Thailand," Journal of Sustainable Energy \& Environment, vol. 1, pp 65-70, 2010.

[9] C. Chiemchaisri and C. Visvanathan, "Greenhouse gas emission potential of the municipal solid waste disposal sites in Thailand," Journal of the Air \& Waste Management Association, vol. 58, pp 629-635, 2012.

[10] V. Wangwacharakul and R. Bowonwiwat, "Economic evaluation of $\mathrm{CO}_{2}$ response options in the forestry sector: the case of Thailand," Biomass and Bioenergy, vol. 8, no. 5, pp. 293-307, 1995.

[11] K. Promjiraprawat, P. Winyuchakrit, B. Limmeechokchai, T. Masui, T. Hanaoka, and Y. Matsuoka, " $\mathrm{CO}_{2}$ mitigation potential and marginal abatement costs in Thai residential and building sectors," Energy and Buildings, vol. 80, pp. 631-639, 2014.

[12] A. Hasanbeigi, C. Menke and L. Price, "The $\mathrm{CO}_{2}$ abatement cost curve for the Thailand cement industry," Journal of Cleaner Production, vol. 18, no. 15, pp. 1509-1518, 2010.

[13] A. Hasanbeigi, C. Menke and A. Therdyothin, "The use of conservation supply curves in energy policy and economic analysis: The case study of Thai cement industry," Energy Policy, vol. 38, no. 1, pp. 392-405, 2010.

[14] A. Hasanbeigi, C. Menke, and A. Therdyothin, "Technical and cost assessment of energy efficiency improvement and greenhouse gas emission reduction potentials in Thai cement industry," Energy Efficiency, vol. 4, no. 1, pp. 93-113, 2011.

[15] The World Business Council for Sustainable Development. (2011). CO $\mathrm{C}_{2}$ and Energy Accounting and Reporting Standard for the Cement Industry. [Online]. Available: http://www.wbcsdcement.org [Accessed: December 2014]. 
[16] Intergovernmental Panel on Climate Change. (2006). IPCC Guidelines for National Greenhouse Gas Inventories. [Online]. Available: http://www.ipcc-nggip.iges.or.jp/public/2006gl/index.html [Accessed: January 2015].

[17] "Thailand Alternative Energy Situation," Department of Alternative Energy Development and Efficiency, pp. 58, 2013.

[18] Thailand Greenhouse Gas Management Organization. (2013). Emission Factors: Carbon Footprint for Organization (CFO). [Online]. Available: http://thaicarbonlabel.tgo.or.th/admin/uploadfiles/emission/ ts_11335ee08a.pdf [Accessed: February 2015].

[19] The World Business Council for Sustainable Development, Cement Sustainability Initiative. (2014). Global Cement Database on $\mathrm{CO}_{2}$ and Energy Information. [Online]. Available: http://www.wbcsdcement.org/ index.php/key-issues/climate-protection/gnr-database [Accessed: April 2016].

[20] The International Energy Agency and The World Business Council for Sustainable Development. (2009). Cement Tecbnology Roadmap 2009: Carbon emissions reductions up to 2050. [Online]. Available: https://www.iea.org/publications/freepublications/publication/Cement.pdf [Accessed: January 2015].

[21] The Office of Industrial Economics, The Ministry of Industry. (2015). [Online]. http://www.oie.go.th/ academic/statistics [Accessed: April 2016]. 